\title{
6 Accelerator Darlings, Challenges, and Future Plans
}

All accelerators have their showcases of startups they see as their greatest successes. In this chapter, I analyze these accelerator darlings and the reasons they were nominated by my respondents. What is their underlying definition of success? Is it mainly related to the funds raised by accelerator startups or their social impact as well? The other side of success is, of course, failure. Do my respondents see a pattern in why startups fail? Does it come down to team, product, or market? It will become clear from my analyses that there is a multitude of factors related to startup success or failure. Predicting startup performance is a poorly developed discipline, much to the chagrin of accelerator CEOs and investors. But it is clear that traction is indispensable for a startup to grow to the next level.

I next examine the greatest challenges that accelerator executives face - challenges they need to address, challenges that are returning issues, challenges that dominate their management agenda. The chapter ends with a grander view and even some speculation. I asked respondents to share their dreams for the accelerator they run. How does the future look for their accelerator and which changes to their program are they planning?

\section{Success, failure, and showcases}

I asked accelerator executives why some startups are successful whereas others fail and which startups that graduated from their accelerator they are particularly fond of. Let us first examine some of the general accelerators. Predicting startup success is a tricky business, according to Elizabeth Yin of 500 Startups. Her accelerator has invested in over 1,800 startups, "But the funny thing is you just never know how things will go. You don't really know until it's over either way." For her showcases, Elizabeth nominates a number of stellar startups that participated in 500 Startups' seed and accelerator program, most of them B2B: Twilio (pay-as-you-go cloud communications platform), Credit Karma (credit and financial management platform), and Intercom (business messaging services). Twilio went public (IPO) in 2016, while Credit Karma raised \$368 million and Intercom \$115 million. ${ }^{71}$

Picking early winners is a major challenge faced by accelerators. Investor math is a matter of continuous trial and error. Saeed Amidi of Plug and 
Play admits: "We all make mistakes. I had the opportunity to invest in Airbnb but we backed out. We had the opportunity to invest in Facebook really early. But all in all, we have around 20 startups that are close to half a billion valuation." Among Saeed's showcases are Dropbox (a cloud storage service), Lending Club (a peer-to-peer lending marketplace), SoundHound (audio recognition), Prevedere (business performance forecasting), and NatureBox (a healthy snacks delivery service). The funds that have been raised by these showcase examples are impressive: Dropbox raised $\$ 607$ million, SoundHound \$75 million, Prevedere \$9.5 million, and NatureBox $\$ 58.5$ million, while LendingClub went public in $2014.7^{2}$

Danielle D'Agostaro of the Alchemist Accelerator pinpoints what makes startups successful: "The companies that hustle. They know how to execute, they know what they need to get done, and they do it. They don't let hurdles slow them down. If they can't get it in the first way, they try a hundred other ways to do it. They persevere, they are determined, they want to make this happen. I would say the successful ones tend to be the ones that are the hustlers." While the Alchemist is too young to have any graduates that have gone public, there have been about 13 acquisitions. For example, Assemblage (a cloud-based collaboration platform) was acquired by Cisco. Other showcase examples include Oomnitza (IT asset management), which raised \$2.6 million; MightyHive (data-driven marketing), which raised \$2.8 million; and Rigetti (quantum supercomputing), which raised \$3 million. ${ }^{73}$ With regard to Alchemist startups that Danielle herself gets really excited about, she says: "Honestly: the ones that are just world-changing." One of them is Positron Dynamics, which develops anti-matter rockets that would power the fastest spacecraft ever created and could eventually enable interstellar travel. Thinking big in optima forma. Positron is funded by a consortium of visionary investors that includes Peter Thiel, Tim Draper, and Ravi Belani.

At BootUP, Marco ten Vaanholt recently looked into just how successful his startups have been: "I was asking myself how many startups did I have over the last two years since we have this building? Ninety-eight companies, of which about forty graduated. None of them has failed. They have raised over $\$ 280$ million already, and that's not because of us only, but because of the plays of good JuJu: their current valuation is at $\$ 3.5$ billion. That's great. That's an amazing statistic." Marco believes that their success is related to BootUP's family-style and connectivity-style approach on how it does business. "It's a really personal relationship that we are building. It's more focused on giving back and doing the right thing. It's not always focused on making the most money. So it goes back to the DNA of BootUP: furthering 
entrepreneurialism. It's the ecosystem at work." Among Marco's personal favorites is AppMachine (creating mobile business apps), a Dutch company that was accelerated by BootUP. "Within ten months, we showcased real results with real pipeline, with real revenue, and real value. AppMachine was invested at an enormous amount by one of the largest website hosting companies in the world." ${ }^{74}$

When asked whether he could observe a pattern in factors that cause a startup to fail, Prashant Shah of TiE LaunchPad, replies: "I think the question you're asking is the million-dollar question. The question is simple but the answer is not. It's not just team or market conditions. That's too easy. Failure is very hard to predict." LaunchPad's high-risk profile makes it susceptible to failure. "Our plan is that over the life of our fund, we will invest in 40-50 companies. Maybe five of them will be the ones that actually make the fund profitable. Because we invest in early-stage startups with teams that are really first-time entrepreneurs, we know that the risk profile is very high on the fund. We have done three batches now, and in every batch there is always one company that seems to move ahead of the rest of them."

Gary Coover of Samsung NEXT weighs the difference between what makes a startup a success or a failure: "A lot of it has to do with the founders. Experience, tenacity, and knowing how to de-risk the startup are important success dimensions. Failure is often a result of being unable to prioritize efforts, to focus on the wrong things, which reduces the ability to drive real customer traction." Samsung has acquired a number of startups via its in-residence accelerator program, of which Gary gives two showcase examples: Mapzen (an open-source mapping platform) and StickiBoard (a shared family dashboard).

Asking Brian Hoffman about his favorite StartX startups evokes an understandable reaction: "It is like asking parents what their dearest child is." It could be about the founder, the team, the company's mission, its financial performance. Brian gives three examples of successful StartX companies: Periscope (a live video streaming app), which was acquired by Twitter; Life36o (a GPS family locator and messaging app), which raised $\$ 73$ million; and Lily (drone cameras), which raised $\$ 15$ million..$^{75}$ These are highly visible consumer brands, but as Brian indicates, some of the really big tech Stanford innovations - for example in the medical sector - are contributions to deep science that do not become consumer market startups but will be part of high-end enterprise technology. They are successful in terms of their contribution to society but not in terms of their mass visibility.

Cindy Klein-Marmer of Butler Venture Accelerator of Babson College notes that it has had successful student startups in its portfolio. "We have 
undergraduate students who come in and they have run businesses in their high school, they make five figures basically. They are very excited because they are sitting there with 10, 20, 30,000 dollars in revenue. It's not a million in revenue, it's not $\$ 100,000$ in revenue, but some have come pretty close." Cindy gives an example of a student who ran a webhosting business that he started when he was 13, which earned a few million in revenue. This business later became his side business when he decided to launch a startup creating a file-sharing platform.

Specialized profit and non-profit accelerators all share the belief that traction is decisive. Traction determines whether a startup is on the right path; it also reflects product-market fit and team performance. Sunil Bhargava of Tandem believes very strongly that "traction is the key to success. A good team generates traction, and traction makes a team stronger." Sunil estimates that at least six out of ten startups will fail. "A lot of companies fail because they don't get traction for a variety of reasons. Because the founder is not seeing things in the right way and sometimes it is just the wrong thesis. Companies may have a good team, may have a good product, but they aren't able to crack the traction problem." Although Tandem is a relatively recent accelerator and investment fund, Sunil is proud to point to some successes. ZumoDrive is a cloud-based file synchronization and storage service that came to power HP's recent CloudDrive technology. Tandem helped ZumoDrive to pivot its initial product strategy. BashGaming, the casual game maker for social and mobile platforms, is another example. GSN later bought BashGaming for about $\$ 165$ million..$^{6}$ Tile, a Bluetooth item tracker, is a third successful example and was Tandem's first hardware company; it raised $\$ 34$ million. ${ }^{77}$

The Fabric, another recent accelerator, has built up a number of companies of which VeloCloud is the most shining example. It is a $\mathrm{B} 2 \mathrm{~B}$ providing software-defined wide area networking (SD-WAN) that raised \$49 million in two rounds, with Cisco as an investor. ${ }^{7}$ Prem Talreja is proud of The Fabric's role in accelerating VeloCloud: "It was the first startup we did and became a home run, a market leader. They could achieve north of $\$ 500$ million to $\$ 1$ billion validation. It has turned into a rock star market leader, our poster child so to speak."

The Hive, the co-creation studio, has seen over twenty startups go through its program since late 2012, four of which have successfully exited. Kosei, a startup that specializes in recommendation systems, was acquired by Pinterest in 2015; Deep Forest Media, a programmatic mobile marketing company and demand-side platform (DSP), was sold to Rakuten Marketing in the same year; Jobr, which developed a mobile job search 
app, was acquired by Monster Worldwide in 2016; and Nurego, a business operations platform for industrial internet applications, was acquired in early $2017{ }^{79}$ T.M. Ravi explains why he gets so much personal satisfaction from coaching startups: "We play with cutting-edge technology: building software robots that automate customer support and customer software. We are playing with augmented reality and virtual reality. We are working on the frontiers of how we will be living our life in the next 25 years. We are creating something from nothing, and seeing it blossom and succeed. (...) There is no other thrill that is as fulfilling. You personally made it happen and it wouldn't have happened without you."

Niche accelerators have their share of successes and failures. Tom Ferguson of Imagine $\mathrm{H}_{2} \mathrm{O}$, has an interesting view of what makes a startup stronger: storytelling. "The biggest lesson is the importance of storytelling. You have to tell your story as a startup. It's not just marketing visibility, it's about understanding and communicating exactly what your business is about. Your company narrative and the way you tell it is absolutely critical." Nimesh Modak, Imagine's director, adds that startup failure is often related to underestimating the business importance of knowing your customer, of unlocking the market, which directly links to the topic of storytelling: "The better you know your customer, the better you know which story you need to tell." Three startup graduates Tom and Nimesh are particularly proud of are Valor Water Analytics, which transforms water utility data flows worldwide into actionable decision-making through innovative software; Nexus e-Water, which develops $\mathrm{B}_{2} \mathrm{~B}$ water recycling hardware; and WaterSmart Software, which uses mobile and online tools to help water utilities educate and engage their customers to save water and money. These three Imagine $\mathrm{H}_{2} \mathrm{O}$ darlings reflect a breadth of hardware and software technology in different water sectors. Valor Water Analytics was able to raise \$2.8 million, Nexus-eWater \$4 million, and WaterSmart Software $\$ 13.3$ million in funding. ${ }^{80}$

Cleantech Open accelerates quite a number of startup companies throughout the U.S. Ian Foraker names two companies that rank high among his personal favorites. One is PowWow Energy - Cleantech Open 2013 winner - which provides Software as a Service (SaaS) solutions for increasing water use efficiency in the agricultural sector. It raised over $\$ 3$ million in funding, including a grant from the California Energy Commission. ${ }^{81}$ Ian: "One of the things they do is using the power signature of electric pump systems to tell whether there are leaks in agricultural fields. Fascinating technology, excellent founding team, great traction." The other favorite is Vartega - winner of the Cleantech Open 2015 national emerging 
technology prize - which specializes in carbon fiber-reinforced recycled plastic for mass use applications. "This has real significant implications for the growth of the whole recycling industry", Ian claims. Vartega raised $\$ 57,600$ in equity funding and $\$ 250,000$ in grants. ${ }^{82}$

Powerhouse CEO Emily Kirsch selects her five showcase examples based on a variety of reasons: innovation, mission, funding, traction, and diversity. Mosaic, which provides residential solar loans and financing, was what inspired the creation of Powerhouse and recently managed to raise $\$ 200$ million in loan capital. ${ }^{83}$ Powerhive is another of Emily's favorites because it supplies affordable micro-grid electricity for rural homes and businesses in developing countries around the globe, having first launched in Tanzania. PVComplete is a B2B platform for automating solar system design, and UtilityAPI provides instant access to utility bill data that can be used for solar company quotes. Both startups have substantial traction and were able to receive funding from the U.S. Department of Energy along with private capital (UtilityAPI raised $\$ 972,000) \cdot{ }^{84}$ And finally, Sunswarm is a community shared solar farm marketplace that Emily is especially proud of because it was one of the first movers in a huge market. Diversity is also key for Powerhouse: PVComplete and UtilityAPI have female co-founders and CEOs, and Sunswarm has an African-American founder and CEO. "At Powerhouse, it is important that not just our employees but also our founder teams reflect the diversity of our city [Oakland]." Empowering female startup founders and diversity is a major concern of Emily: "Because the bottom line for any company increases when women serve on boards in leadership positions. Less than four percent of U.S. venture capital goes to women, which is pathetic. What's even more pathetic is that one percent of venture capital funding goes to African-Americans and Latinos. ${ }^{1{ }_{5}}$

Empowering female startup founders is the core business of Women's Startup Lab. Ari Horie notices that, after completing her accelerator program, founders gain a new level of confidence, have better networks, receive referrals, have access to funders, and have the right mindset and skills to be successful. Red Clay, a platform that connects brands to freelance industrial designers to turn product ideas into manufacture-ready technical files, has a prominent place in Women's Startup Lab's showcases. "We helped the founder with introductions to the circuit, and all those people were like, wow, she's great. She got a lot of attention, referral after referral, and she just took off." Red Clay raised \$1 million in equity funding. ${ }^{86}$ Another success story is Babierge, a platform that connects travelers with baby gear rentals (for example in airports), which has expanded to almost 30 locations in the 
U.S. and Canada. In this case, too, the founder's increased confidence and network introductions made the difference.

I conclude this section by evaluating the five accelerating platforms. Prospect SV is a young innovation hub and demonstration platform launched in 2014. Founder Doug Davenport nominates ConnectMyEV, which provides smart and hands-free conductive chargers for electric vehicles, as one of Prospect's showcases. "This startup client is developing prototypes and is working with one of the largest car companies in the world. It's very, very interesting stuff." Thomas Power is another case. It works on retrofitting transit diesel busses in their mid-life stage by sustainable energy software and power management systems that transform them into hybrid and electric means of transportation. Doug reveals that the founder "is a really smart person who's got incredible experience and is leading a team in three countries. This startup client has gotten a couple of investment rounds and is starting on multi-million-dollar pilot projects."

Established in 2012, GSVlabs does not have a long track record, but Marlon Evans tells me that a few companies have already done very well. "A good example is an Australian company, LIFX, that raised over \$15 million. We just had another company acquired by WeWork. More of those stories will be coming up, as we are still a young company." LIFX distributes Wi-Fi enabled, multi-colored LED lights controllable via a smart device.

When asked about his favorite successful startups, Runway's Matt Walters does not need to think long. One is Atomwise, which develops artificial intelligence systems for drug discovery: it raised $\$ 6.3$ million. ${ }^{87}$ "This is really cutting-edge data modeling using super computers and deep learning to simulate the effects of drugs from a compound of thousands of approved medicines that might, for instance, cure Ebola or MS. They partner with Merck, one of the largest pharmaceutical companies in the world." His second pick is Skycatch, which develops drones to analyze the progress at large construction industry sites delivering precision aerial mapping and ${ }_{3} \mathrm{D}$ models. It managed to raise over $\$ 41$ million. ${ }^{88}$ "This, too, is fascinating technology. These drones are fully autonomous and self-charging, so they provide 24-hours continuous coverage." Skycatch partners with Komatsu, the world's second-largest construction equipment manufacturer.

Hacker Dojo's Jun Wong has a two-part answer to my question on the successful startups that came out of the Dojo. "What would the definition be? Well, I'll answer it the easy way and the hard way. In terms of market valuation, Pinterest is one of our showcases. But there are much smaller ones that launched good projects, creative projects, projects with an impact. We had a group here that was able to make a self-driving robot which you can 
drive around, recognizes people, and knows how to navigate. They were able to make this prototype out of $\$ 500$ worth of material." Pinterest, the popular visual bookmarking tool for saving and discovering creative ideas, is in a different league: it raised total equity funding of $\$ 1.3$ billion and is currently valued at $\$ 11$ billion. ${ }^{89}$

RocketSpace's founder and CEO Duncan Logan attributes the success of his accelerator to its competitiveness, its infectious environment, and its entrepreneurial drive, in addition to the rigorous selection process. "This is Real Madrid [one of the most successful professional soccer clubs in Europe]." As a consequence, Duncan adds, "We've had an incredibly low failure rate. Of the $75^{\circ}$ or so startup companies that have been through RocketSpace, the failure rate is about 15\%." Uber, Spotify, and Zappos are among RocketSpace's famed alumni that went on to disrupt traditional markets and have a tremendous impact on consumer behavior.

To summarize, financial performance is a major element of how accelerator executives evaluate their startups' track record, particularly in terms of the amount of funding raised, whether or not they were acquired by a larger company, and whether they went public. Traction appears to be a determining factor in whether a startup will be successful or end in failure. Traction makes or breaks a startup. But this is not the whole story: innovation impact, social leverage, and market disruption were also named as important aspects of startup success. Many of the favorites chosen by accelerator executives succeeded in valorizing fascinating applications of breakthrough technologies.

\section{Challenges and future plans}

In this section, I examine some of the challenges that accelerator executives face and the business dreams they have for the near future. What strategic issues do they feel they need to address, and what innovations do they want to implement? Do accelerator founders and CEOs see a need for pivoting their business strategy?

At Plug and Play, one of the challenges and future plan is further expansion at both the national and international levels. CEO Saeed Amidi elucidates: "I want to have an innovation platform and accelerator on top of it. We just opened accelerators in China, Paris, Stuttgart, Berlin, and Amsterdam, and we may do New York City, London, and others in the future. Accelerators provide incredible opportunity for people to meet. They might be corporations from an industry that is being disrupted, or 
they might be from the venture world that is looking for investments." This expansion strategy is part of a larger scheme that Saeed dreams of realizing - a dream that consists of numbers and impact - personal impact, to be precise. "I have made a positive impact in about 6,0oo startups since I opened Plug and Play. As I said, we recently opened new offices in China and Europe. My dream is that I would love to make a positive impact in like 10,000 startups; a 1,000 new ventures per Plug and Play vertical, and really change the industry. Half of it U.S., and half international. And then with all the startups in Germany, France, Spain, China, etc. we build a bridge to the mothership here in Silicon Valley. Their engineering teams could stay in Europe or Asia, but they have their headquarters here. That gives them access to the $\$ 6$ billion to $\$ 10$ billion market cap in the Valley."

Elizabeth Yin of 500 Startups has no grand plans for her accelerator but underlines that the accelerating startup program itself is a dynamic one. "It's a different program than it was a few years ago. And I fully expect that in another few years it will change again. I would love to grow our batches. But at this moment we are not anticipating building any accelerators outside the Bay Area. We may just increase the size of our batches." And what about 500 Startups' international ambitions? "Half of our investment partners are located outside of the U.S.: Europe, Asia, Middle East, Latin America. They help us with scouting startup companies and bring them here for the program. For fundraising, for the ecosystem, Silicon Valley remains one of the best places in the world. It makes sense to be here."

One of the challenges faced by accelerators that do not require mandatory program attendance is the danger of community erosion, of not building a strong startup batch culture. Danielle D'Agostaro of Alchemist Accelerator recognizes this challenge. "We need a balance. That's why we also have social events outside of just the educational components as well. There definitely is a stronger community between the people that show up regularly. We are also a little bit more open towards live streaming of our expert talks and founder presentations than we were before. It's a balancing act." But the majority does participate. They pay for the program, and many international founders move all the way out to Silicon Valley in order to attend the program. International expansion is on Alchemist's agenda. "We are actually in talks right now with some people who want to take Alchemist internationally, and we are looking at possible locations. I think in three years, Alchemist is not only going to be a Silicon Valley accelerator, and it's probably going to have its brand expanded, and not just in Europe."

Founders Space is a general but smaller accelerator. It has an international outreach but doesn't plan to turn the company into a mammoth 
accelerator. Naomi Kokubo says: "We've had investors requesting to invest in Founders Space. But we said no. We don't need the outside investment. But we are interested in setting up a good institutional venture fund not investing in us but in our startups." Founders Space would prefer to organize its international ambitions by using different templates, for example by franchising its model. "Having cobranded accelerators in China, Europe, Middle East, Asia, South America, and other parts of the world, with their independent organization and staff - this approach works very well." In May 2017, Founders Space announced that it was opening a branch in Chengdu, with other Chinese cities to follow.

TiE LaunchPad is also a smaller accelerator. Prashant Shah points to a challenge that is size-related. "Because we are so highly selective, the challenge is whether our present number of startups of about ten companies a year is sufficient to keep the program going. If we are only investing in a handful of startups, then the returns get longer as well. We are at a slower investment pace than most other venture funds, and that means that we have to start raising our next fund pretty early on." Does this self-diagnosis imply a pivot of the LaunchPad's main strategy? "Well, maybe. A solution might be that we have to invest in startups directly, even if they are not part of our program. See ourselves as angels." And in fact that is what LaunchPad recently decided to do: to continue as TiE Angels.

BootUP's Marco ten Vaanholt is passionate about the strength of Silicon Valley's ecosystem but also sees a serious challenge. "The climate here is that we have so many accelerators, everybody takes an equity position in early-stage startups between five and eight percent for 50-10oK. That is a lot of money for a startup to give away- a lot of money for what is sometimes not more than a three-month pitch training. And then send them out into the world with $\$ 50,000$. That's the downside." It is a model, according to Marco, that no serial startup entrepreneur is willing to accept. "What startups need is traction. And in traction they are willing to give up retainer fees, to give up revenue share, and only then they are willing to give up equity. Traction before funding, not the other way around. No funding before traction." This is just one step to Marco's dream for the future. "I want BootUP to become the de facto 'tractionator' of the world. I get the better startups with better survival prospects. I find it ridiculous that such a small percentage of startups succeeds." Part of Marco's dream is to work with European corporate partners and accelerate their startups in Silicon Valley. "BootUP built the ecosystem for doing so."

Does a corporate accelerator such as Samsung NEXT encounter different challenges than non-corporates? Yes and no, according to Gary Coover. 
"We want to make sure that we are leveraging the strengths without also suffering from the perceived weaknesses of a large corporate." Competition for talent is a shared challenge. "There is definitely competition for talent. It's hard for good startups to hire great engineers, and it's hard for great accelerators to attract great talent. As a result, we think a lot about how we compete, how we can be different."

Cyril Ebersweiler, founder and managing director of HAX, raises a completely different challenge: what exit strategy will accelerators develop for themselves, not just for the startups they help grow? "What we soon will see is actual liquidity coming out of accelerators. They are creating enormous value for themselves. I think that accelerators will either be bought or they will go IPO. This really will change the playing field." If Cyril's prediction would become reality, it would certainly affect the way accelerators operate, their business model, the startups they seek to grow, their investment strategy, and the ROI they are after. It would impact the business parameters of accelerators in the future. What about HAX's own future? What are Cyril's dreams with respect to his own accelerator? "I would like to take on bigger projects. One is about building a new city. It is a ten-year program, but there are ways to do that. HAX Infra will play a major role. In three years, Infra will have a hundred companies that have the potential to implement a hundred technologies at the city level. I don't even know how to define it, but it is going to be fascinating. It's going to be big."

What are the challenges that university-linked accelerators encounter, and what are their plans for the future? StartX wants to rethink its business model. Says Brian Hoffman: "Our business model has some constraints in that we are limited in the number of our partners we can take because we are limited in the number of startups, we have a ten-week calendar. The assets that we have to provide to our partners do get diluted if we increase their number." This scaling issue is somewhat typical for a non-profit accelerator, Brian states. "When we started in 2010, we had a batch of eight companies, everyone was under twenty-five, doing it for the first time, and lived right around here. It's easy to build a community in a small ecosystem where people have so much in common. But as we grew we needed to professionalize, set up an organization, hire staff, be relevant to everyone." One of the challenges StartX as a general accelerator is facing is the issue of specialization, of finding the right balance between scaling, added value, and support quality. "We don't have to have that specialist value because we are a kind of lifelong Stanford network you can leverage, but we do need to have added value to every type of founder. How do you launch verticals, how can you be relevant to super specialized PhD teams?" 
The Butler Venture Program of Babson College is a dynamic enterprise. "We are constantly changing" says Cindy Klein-Marmer. "I look at the accelerator as our startup, with me and my team members as founders. We are continuously tweaking and taking lessons on; there are constant iterations. This fall, we will roll out a new level of accountability and community." Cindy tells me that the San Francisco summer venture pilot, which they first ran in 2016, will be evaluated. Should it be made permanent? Could it be done remotely? Does it need to be on the West Coast? Does it need to be in the U.S.? These are all questions that come up for an accelerator as a learning enterprise, as a startup indeed. The Babson Venture Program also has international ambitions. "Through our new Babson collaborative, we are looking for a way to have additional accelerators and incubators, essentially around the world, based on a pay-to-play model. The opportunities are endless right now. It also makes sense with Babson's centennial anniversary coming up in 2019."

The specialized high-touch accelerators, including the smaller niche players, have their own concerns. Tandem, the hands-on mobile accelerator, understands that timing is everything. Sunil Bhargava has a clear view on Tandem's main challenge, one that holds for all quality-conscious accelerators: "I think the key challenge is finding the right team at the right moment. If the right team approaches us too late, it doesn't fit our model. If they approach us too early, it doesn't work either." For the future, Tandem is ambitious. Sunil: "My goal, you know, is more of a mission: to help out entrepreneurship on a global level. We want to do more startups that come from different parts of the world, help them build their company, and connect them to U.S. markets. The mission is having an impact on as many entrepreneurs as we can get through."

Prem Talreja of The Fabric defines a set of more practical challenges. "We decided that once we commit funding, we have to work with more stringent milestones. Funding is not a gift but needs timely accomplishments." The recruitment of founders also raises concerns, particularly with respect to mindset and expectations. "We have felt that people left their cushy jobs to come to us with the dream of becoming somebody that they were not ready for. There is a sense of comfort that they expect from a life as a startup entrepreneur, a life that actually is very uncomfortable - lots of stress, financial concerns, impact on your family and personal life. I've been there; I know what I am talking about." Managing growth is another issue that The Fabric is working on: "We have to focus more on ensuring the startups get future rounds of funding. Their success will help us refill our fund. Our intention is not to become a large organization. It would 
mean we have to expand our management team, solve lots of managerial problems. We are not like that."

At The Hive, T.M. Ravi's plans for the future reflect an energetic mix of passion, ambition, and impact: "Continue to create and launch exciting companies, help make their dream and the vision around artificial intelligence and its market potential become real - so real that it changes our lives - and see our startups go to greater and greater stages of success." The Hive's main focus is in Silicon Valley, but as part of its international expansion it has created The Hive India and The Hive Brazil. "We have sort of put The Hive in a box and made it easily transferrable to other regions. Some regions just don't have the innovation ecosystem, the capital, or the talent pool, so I wouldn't say it expands to everywhere but to some regions it definitely is. We are exploring some of them."

What are specific challenges that the four niche accelerators encounter? What about their plans for the future? Cleantech Open is a pro bono volunteer organization, which it believes is a major asset but also one that demands further professionalization. A volunteer organization typically faces challenges in the areas of structured coordination, less fluid participation, the creation of consistency and continuity, and the securing of institutional memory. In the words of Ian Foraker: "I think our core model is good, but it can be refined. We're always looking at ways we can make it more robust and leverage the asset we have. I'm eager to professionalize our model. We want to further standardize our main processes." One of these challenges has to do with fine-tuning Cleantech Open's admissions policy. "We are a mission-driven organization and therefore we want take as many viable startup companies in our accelerator program as possible. We have no shortage of mentors. In fact, we have mentor pools we can't leverage enough." The mission of Cleantech Open is to advance the use of sustainable resources and market-smart solutions to pressing environmental and energy issues. Ian states that the task for the near future is to create more value in realizing this commitment. "We need to move from being a passive catalyst to becoming an active catalyst. How do we not only educate entrepreneurs but actively evaluate the gaps and plug those gaps. We really want to expand our global footprint by connecting the dots across the globe. If we want to effectively fight global warming and climate change, we need to increase the bringing to market of innovative clean technologies by a factor ten or more."

For Imagine $\mathrm{H}_{2} \mathrm{O}$, "The challenge number one is to blow the minds of the entrepreneurs that take our program. We want them to be successful and our best evangelists possible." Having made this statement, Tom Ferguson points to a number of practical issues such as finding the right balance 
between training entrepreneurs and working remotely, and developing metrics to monitor the effectiveness of their programs. In terms of the future, Imagine $\mathrm{H}_{2} \mathrm{O}$ 's ambitions include further globalization. Nimesh Modak explains: "We want to explore how we can support startup companies from around the world. So much of the value we offer is through our mentorship program. In order to support startups in other countries, we need to expand our mentor and partner network. That is something we are quite aggressively pushing forward right now. It would really capitalize on the values of Imagine $\mathrm{H}_{2} \mathrm{O}$ being a vertical accelerator."

In the solar energy industry, Emily Kirsch of Powerhouse reckons that "the biggest challenge is that not enough people are applying their skills to the solar industry yet. Eventually solar will be everywhere, it will power all of our lives, it will be built into our clothes, iPhone, and laptop covers, powering our homes and cars. This will all happen through innovative ways to produce and manage the distribution and storage of energy. And it all requires hightech and funding." Her greatest worry is that in spite of the enormous opportunity that solar presents and how big it is going to be in the near future, we are going to need much more talent and many more solar startup entrepreneurs. In the U.S., Emily discloses, there are 40 million rooftops that are suitable for solar, which would expand to 90 million households if apartments and condos are included. "We've only just begun scratching a tiny, tiny bit of the surface of what is possible." Emily predicts a bright future for community solar farms. "It's even going to be bigger than rooftop solar." Entrepreneurial talents and talented entrepreneurs are needed to make this radical energy transformation.

Ari Horie of niche accelerator Women's Startup Lab tells me that her organization is expanding with a venture division and a co-working division. She's moving the startup lab "beyond" the core business of an accelerator, thereby moving to a new stage of her lab's story with much more emphasis on lifelong education and platforms for women entrepreneurs. The new program will focus on batches of "the nine best and brightest female entrepreneurs". In Chinese numerology, the number nine has a very positive connotation and stands for luck, creativity, imagination, dream realization, and care. Ari's dream is to set up the new model in a way that is scalable and that makes Women's Startup Lab into a global entrepreneurship brand podium that supports female entrepreneurs in launching and growing their companies. She aims for it to be a model that helps women to thrive and succeed, where meaningful relationships and new technology bring unlimited opportunity. 
And what are the challenges and future plans of the five accelerator platforms that feature in my study? Prospect SV is an innovation hub and demonstration center that works with corporate sector players, innovative startups, cities, agencies, and the research community - a complex field of stakeholders according to Doug Davenport. The challenge? "It's just incredibly hard to actually make that become a symphony, right? We could teach classes on this. At the end of the day, you need momentum. The problem is that the market isn't moving fast enough for there to be any pull of ideas in." Prospect helps Bay Area cities in becoming smart and sustainable communities. "The biggest problem is that 108 cities in the Bay Area are not acting as a 108 division region. They're all individual, independent entities, sometimes at cross purposes with each other. Our biggest challenge here is to help build the business case in those cities." Doug's ideas for the future are directly related to addressing these challenges. One is to help elevate innovation leadership and early technology adoption amongst certain cities and develop cases that other cities can learn from. "That would be fantastic." The other is to promote capability development among industrial stakeholders - e.g., the building industry - to help them understand how they can benefit from new technologies. "Such a focus on design feedback and market intelligence could make a unique program."

One of the challenges that Marlon Evans of GSVlabs shares is determining the basics of his accelerator's expansion model. Which new domestic and international markets are suitable? How do you get there? What are the business model implications, and what funding do you need? "If you look at a market like China, I think there are like 10,000 accelerators, probably a new accelerator a day that's starting up. How do we play in that environment, and does it make sense to start a new accelerator or do we service as a hub that these other accelerators can use as a resource"? GSVlabs' model will change as markets develop, says Marlon, "but the core will always be working with startups. The value added that we could provide is going to be more of a platform ecosystem where ideally we support accelerators that move into new markets. A kind of retail model. A kind of scaling model."

Runway is also re-examining its business model. At present, it combines co-working incubation space with a specialized EdTech accelerator. Matt Walters sketches the challenges and ambitions: "We are considering doing additional acceleration programs in other fields. We are debating whether this makes sense, or could we instead just have our incubator and then have a fund and invest in the startup companies without having to run additional programs." A more practical challenge is for Runway to track more metrics on how their startup companies are doing: monitoring traction, investments, 
funding, etc. "We want to be more analytic-driven, we want to measure impact." Like GSVlabs' Marlon Evans, Matt points to the rapidly growing number of accelerators. "Every week I hear about another one popping up. The challenge for us is to make sure that we are continuing to deliver value, that we really provide the services and resources out there." And as with other accelerators, Runway has global ambitions: "The dream is to have Runway locations around the world. So we are going out to South America, we are going out to East Asia to create a global network. I think there is something powerful about being able to connect different geographies."

The biggest challenge for Hacker Dojo, according to Jun Wong, is real estate. "Because we are non-profit, we want the Dojo to be accessible to everyone. But there is a huge cost in operating this place as rents get higher and higher." What is also high is Hacker Dojo's ambition. "We're trying to raise a really big fund so that we can purchase a campus. That's our goal for the next three years." Hacker Dojo furthermore wants to refine and expand its open model of self-education. "We would like to have a broader approach in which our members can learn from others by bringing in people that are leaders in their field and discuss and share their experiences. That would be a very 'Dojo-esque' kind of thing."

RocketSpace intends to go global, as Duncan Logan explains: “We've been working a lot on this. We started here in Silicon Valley because it's a kind of mecca for technology, but I think there are ecosystems elsewhere around the world that would work for us. We might put a RocketSpace in London or Amsterdam, Berlin or Tel Aviv, or Singapore or Shanghai. And we just focus on the top 200 companies and then we connect them together." In April 2017, RocketSpace opened its first European co-working campus in London. ${ }^{90}$

\section{Conclusion}

The success or failure of a startup is hard if not impossible to predict, according to Silicon Valley accelerator executives. Forecasting a startup's success is more intuitive than hard science. Predicting startup success is a Herculean undertaking. But in every scenario traction is key. Customer traction is the conditio sine qua non for startup growth. Scalability is essential. The startups that respondents selected as their showcases are the ones that raised considerable external funding, which is, of course, traction-related. The products or services launched by these favorites are believed to have a significant social impact as well. Accelerator founders and CEOs are intrigued by cutting-edge technologies that address urgent short 
or long-term issues and that develop solutions that disrupt markets. Most of them are market and mission-driven. Scalability and market prospect is what defines startup potential, and to develop this potential requires experience, tenacity, and team prioritizing. But even then, there is no single path to success. What are some of the most common mistakes founder teams make in this context? Seasoned mentor and Silicon Valley connoisseur Susan Lucas-Conwell does not have to think long: "The most deadly one is when the team is solving a problem that nobody cares about. The next one is that the team works on a solution that nobody wants to pay for."

One challenge was mentioned by nearly all my respondents: talent. All accelerators are looking for talented startup teams. Regardless of sector, mission, profit or non-profit status, size or program, an accelerator's primary concern is getting access to talent and recruiting talented startup founders. Accelerator executives feel that they are all competing for the best startup teams. Additional challenges include specialization, further professionalization, increasing cohort size, stakeholder alignment, and the need for monitoring startup performance by using more advanced metrics.

High tech is essentially global: it is not restricted to geographical markets, boundaries, or national entities. It is interesting that so many Silicon Valley accelerators indicate that going global is among their priorities in the near future. Most accelerators have international ambitions and want to expand to other regions and countries. 'Global branding', 'global franchising', 'global outreach', 'global connectivity', and 'global platform and hub' are expressions the accelerator executives use to illustrate their international aspirations. The typical global strategy of accelerators has been to train international startup teams in Silicon Valley. Now they see that other countries and regions are becoming interested in developing innovative ecosystems as well. This leads to a reverse strategy in which accelerator branches are to set up in other parts of the world. The underlying dream is not only based on broadening their geo-economic investment calculus but also inspired by a deeper mission of having a global impact on fostering entrepreneurship. 
